\title{
COMPARAÇÃO ENTRE MÉTODOS PARA DETERMINAÇÃO DE CARBONO ORGÂNICO EM AMOSTRAS DE SOLO MENSURADAS POR VOLUME OU MASSA ${ }^{(1)}$
}

\author{
Thalita Fernanda Sampaio ${ }^{(2)}$, Dirceu Maximino Fernandes ${ }^{(3)}$, Iraê \\ Amaral Guerrini( ${ }^{(3)}$, Julio Cesar Bogiani( ${ }^{(4)} \&$ Clarice Backes $^{(5)}$
}

\begin{abstract}
RESUMO
O uso da massa (g) ou do volume $\left(\mathrm{cm}^{3}\right)$ como medida da quantidade de solo para determinação do teor de $\mathrm{C}$ orgânico do solo (COS), bem como a utilização de diferentes métodos de determinações analíticas empregados para essa mesma finalidade, pode alterar diretamente a interpretação dos resultados. Este trabalho teve como objetivo comparar os métodos colorimétricos e titulométricos de determinação de matéria orgânica em três solos com diferentes texturas, tomando-se as amostras por massa (pesagem) e por volume (cachimbagem). Houve variação no teor de COS entre os métodos estudados para um mesmo solo. O uso da massa e do volume alterou diretamente a interpretação dos teores de matéria orgânica no solo. Há variações nos métodos de determinação de COS entre solos de diferentes texturas.
\end{abstract}

Termos de indexação: carbono orgânico, colorimetria, titulometria, textura de solo.

\section{SUMMARY: COMPARISON BETWEEN METHODS OF ORGANIC MATTER DETERMINATION IN SOIL SAMPLES BASED ON VOLUME OR MASS}

The use of mass (g) or volume $\left(\mathrm{cm}^{3}\right)$ as a measure of the amount of soil for determination of soil organic matter (SOM), as well as methods of quantitative analysis used for the

\footnotetext{
(1) Trabalho apresentado em congresso: Fertbio 2010. Recebido para publicação em 20 de janeiro de 2011 e aprovado em 2 de fevereiro de 2012.

(2) Doutoranda, Faculdade de Ciências Agronômicas - FCA/UNESP. CP 237, CEP 18610-370 Botucatu (SP). E-mail: tfsampaio@fca. unesp.br

(3) Professor Assistente/Titular/, Faculdade de Ciências Agronômicas - FCA/UNESP. Bolsistas do CNPq. E-mails: dmfernades@fca. unesp.br; iguerrini@fca.unesp.br

(4) Eng.-Agrônomo, EMBRAPA. Caixa Postal 174, CEP 58107-720 Campina Grande (PB). E-mail: julio@cnpa.embrapa.br

(5) Pós doutoranda, Faculdade de Ciências Agronômicas - FCA/UNESP. E-mail: claricebackes@hotmail.com
} 


\begin{abstract}
same purpose, can directly affect the interpretation of results. Therefore, the methods of titulometric and colorimetric determination of organic matter were compared in three soils with different texture, sampling the soil based on mass and on volume. The organic matter content determined for a same soil differed between the methods. The use of mass or volume directly affected the interpretation of organic matter contents in soils with different texture.
\end{abstract}

Index terms: Organic carbon, colorimetric, titration, soil texture.

\section{INTRODUÇÃO}

A matéria orgânica do solo (MOS) é um composto à base de $\mathrm{C}$, proveniente totalmente de material orgânico (Silva \& Mendonça, 2007). $\mathrm{O} \mathrm{C}$ pode ser armazenado nos compartimentos da MOS, melhorando as características físicas e químicas do solo (Vasconcelos et al., 2010; Cunha et al., 2011; Cardoso et al., 2011), ou liberado para atmosfera, intensificando o efeito estufa (La Scala Jr. et al., 2001). Dessa forma, o teor de MOS altera diretamente a qualidade e produtividade do solo, sendo, por isso, extremamente importante sua determinação.

A quantificação do $\mathrm{C}$ tem sido realizada empregando-se métodos que determinem a forma total (CT) ou orgânica do C no solo (COS). Esses métodos vêm sendo modificados e, ou, adaptados à rotina dos laboratórios (Gatto et al., 2009), porém há carência de informações consistentes quanto à definição e recomendação do método mais adequado, sobretudo para solos com elevados teores de MOS (Conceição et al., 1999).

Os métodos baseados na oxidação do $\mathrm{C}$ pelo dicromato $\left(\mathrm{Cr}_{2} \mathrm{O}_{7}{ }^{2-}\right)$ têm sido os mais usados em pesquisas e análises em laboratórios de rotina, pois são de simples execução (Gato et al., 2009), dispensam o uso de equipamentos especializados, além de apresentarem boa exatidão e oxidarem as frações de MOS mais reativas (Tedesco et al., 1995). Esses métodos baseiam-se na redução do $\mathrm{Cr}_{2} \mathrm{O}_{7}{ }^{2-}$ por compostos de COS e subsequente determinação do $\mathrm{Cr}_{2} \mathrm{O}_{7}{ }^{2-}$ não reduzido por titulação de oxirredução com $\mathrm{Fe}^{2+}$ ou por técnicas colorimétricas (Nelson \& Sommers, 1996), destacando-se os métodos volumétricos e colorimétricos.

Tanto no método volumétrico como no colorimétrico a oxidação do COS é obtida com uma mistura de $\mathrm{Cr}_{2} \mathrm{O}_{7}{ }^{2-}$ e ácido sulfúrico. A determinação pelo método volumétrico (Walkley-Black) consiste da titulação do excedente de $\mathrm{K}_{2} \mathrm{Cr}_{2} \mathrm{O}_{7}$ colocado na amostra com sulfato ferroso amoniacal. Pelo método colorimétrico, a determinação do COS baseia-se na leitura direta da intensidade da cor verde do íon cromo reduzida pelo COS (Quaggio \& Raij, 1979), por meio de espectrofotômetro. O método colorimétrico é uma modificação do método Walkley e Black, proposto para medir a MOS facilmente oxidável ou decomponível do solo (Walkley \& Black, 1934; Walkley, 1947).

Conforme Raij \& Bataglia (1991), Nelson \& Sommers (1996) e Raij et al. (2001), o teor de COS determinado por titulação apresenta maior exatidão; entretanto, em laboratórios que manuseiam grande número de amostras seu uso torna-se mais restrito, pelo tempo gasto nas titulações (Embrapa, 1999). Dias et al. (1991) afirmam que, para trabalhos de rotina em laboratórios, os métodos colorimétricos apresentam como vantagem principal a economia de reagentes e tempo gasto com as análises.

Correlações têm sido encontradas entre os métodos volumétricos e colorimétricos de determinação de COS (Dias et al., 1991); o problema é que, além do método a ser empregado, outra discussão tem sido levantada: o uso do volume ou massa de solo para quantificar o COS das amostras (Lierop, 1989; Abreu et al., 1997). Na maioria dos laboratórios é comum a adoção de medidas de volume de solo usando um utensílio chamado "cachimbo". As amostras de solo, após secas e peneiradas, apresentam densidades diferentes daquelas do mesmo solo em condições de campo (Raij \& Grohmann, 1989), sendo essas diferenças maiores em amostras de solo com alto teor de matéria orgânica ou em solos orgânicos.

Dessa forma, o uso da massa ou volume pode alterar diretamente a interpretação dos resultados de análise de COS. Este trabalho teve como objetivo comparar dois métodos de determinação de COS em três solos com diferentes texturas, em amostras medidas por volume ou massa.

\section{MATERIAL E MÉTODOS}

As amostras de solo foram coletadas em três sítios com texturas diferenciadas de um fragmento de mata da fazenda experimental Edgárdia, pertencente à Faculdade de Ciências Agronômicas de Botucatu/UNESP, caracterizados como: sítio 1 Nitossolo Vermelho (NV), textura argilosa, altitude de $700 \mathrm{~m}$, relevo ondulado e ocupado por capimnapier (Pennisetum purpureum); sítio 2 - Argissolo Vermelho-Amarelo (PVA), textura média, altitude 
de $574 \mathrm{~m}$, relevo suave ondulado a ondulado e ocupado por um remanescente florestal; sítio 3 Latossolo Vermelho (LV) - teor de argila da camada superficial < $15 \%$ - textura arenosa, altitude de $540 \mathrm{~m}$, relevo plano a suave ondulado, ocupado por uma mata secundária em médio estádio de regeneração bastante perturbado, tendo sofrido extrações seletivas de madeira e queimadas.

Para determinação do COS do solo, foram utilizadas 40 amostras de cada sítio, coletadas na profundidade de $0-20 \mathrm{~cm}$. Após coletadas, as amostras foram armazenadas em sacos plásticos para posterior secagem ao ar (terra fina seca ao ar - TFSA) e passagem em peneiras com malhas de $2 \mathrm{~mm}$ de abertura. Os métodos analíticos avaliados para determinar o teor de COS foram o colorimétrico e o volumétrico, tomando-se as amostras de solo por massa ou por volume para cada um deles, resultando em quatro tratamentos:

a) Volumétrico, descrito por Walkley-Black e amostras mensuradas em volume.

Cachimbou-se $1 \mathrm{~cm}^{3}$ de solo (TFSA) para um erlenmeyer de $500 \mathrm{~mL}$ e adicionaram-se $10 \mathrm{~mL}$ de $\mathrm{K}_{2} \mathrm{Cr}_{2} \mathrm{O}_{7} 0,5 \mathrm{~mol} \mathrm{~L}^{-1}$ e $20 \mathrm{~mL}$ de $\mathrm{H}_{2} \mathrm{SO}_{4}\left(18 \mathrm{~mol} \mathrm{~L}^{-1}\right)$ $+\mathrm{Ag}_{2} \mathrm{SO}_{4}$ (0,04 mol L-1); agitou-se por um minuto e deixou-se em repouso por $30 \mathrm{~min}$; adicionaramse $200 \mathrm{~mL}$ de água destilada, $10 \mathrm{~mL}$ de $\mathrm{H}_{3} \mathrm{PO}_{4}$ $\left(14,66 \mathrm{~mol} \mathrm{~L}^{-1}\right)$ e $1 \mathrm{~mL}$ de difenilamina $\left(0,03 \mathrm{~mol} \mathrm{~L}^{-1}\right)$; titulou-se o excesso de oxidante com $\mathrm{FeSO}_{4}$ $0,5 \mathrm{~mol} \mathrm{~L}^{-1}$ até viragem de azul para verde; fez-se a titulação de uma prova em branco. O COS foi determinado conforme Raij et al. (2001).

b) Volumétrico, descrito por Walkley-Black e amostras mensuradas em massa.

Fez-se o procedimento analítico citado em "a", diferenciando na forma de mensurar as amostras de solo. Para amostras com menos de $2 \%$ de MOS, pesaram-se 2 g de solo; amostras com 2 a $4 \%$ de MOS, 1 g de solo; amostras com 4 a $10 \%$ de MOS, 0,5 g de solo; amostras com 10 a $20 \%$ de MOS, $0,25 \mathrm{~g}$ de solo; e amostras com mais de $20 \%$ de MOS, $0,1 \mathrm{~g}$ de solo (Tedesco et al., 1985). Neste trabalho foram usados $0,5,1,0$ e $2,0 \mathrm{~g}$ de solo, conforme a estimativa do teor de MOS obtido em "a".

c) Colorimétrico, descrito por Raij et al. (2001) e amostras mensuradas em volume.

Mediu-se $1 \mathrm{~cm}^{3}$ de solo (TFSA) e adicionaramse $10 \mathrm{~mL}$ de $\mathrm{Na}_{2} \mathrm{Cr}_{2} \mathrm{O}_{7}\left(0,667 \mathrm{~mol} \mathrm{~L}^{-1}\right)$ em ácido sulfúrico $\left(5 \mathrm{~mol} \mathrm{~L}^{-1}\right)$; agitou-se durante $10 \mathrm{~min}$ em agitador com movimento circular-horizontal a 180 rpm; após repouso de uma hora, adicionaram-se $50 \mathrm{~mL}$ de água, deixando decantar durante $12 \mathrm{~h}$; separou-se o sobrenadante e realizou-se a leitura em espectrofotômetro com filtro de transmissão máxima de $650 \mathrm{~nm}$; acertou-se o zero do aparelho com a prova em branco. Os resultados foram calculados a partir da curva-padrão, preparada pelo método volumétrico (Raij, 2001).

d) Colorimétrico, descrito por Raij et al. (2001) e amostras mensuradas em massa.

Fez-se o procedimento analítico citado em "c", diferenciando na forma de mensurar as amostras de solo. Para amostras com menos de $2 \%$ de MOS, pesaram-se 2 g de solo; amostras com 2 a $4 \%$ de MOS, 1 g de solo; amostras com 4 a $10 \%$ de MOS, $0,5 \mathrm{~g}$ de solo; amostras com 10 a $20 \%$ de MOS, $0,25 \mathrm{~g}$ de solo; e amostras com mais de $20 \%$ de MOS, $0,1 \mathrm{~g}$ de solo (Tedesco et al., 1985). Neste trabalho foram usados $0,5,1,0$ e $2,0 \mathrm{~g}$ de solo, conforme a estimativa do teor de MOS obtido em "c".

Foram analisadas em laboratório de fertilidade do solo 40 amostras de cada sítio experimental, com três repetições cada. Os dados foram submetidos à análise de variância, e a comparação das médias foi feita pelo teste de Tukey $(\mathrm{p}<0,05)$. Os resultados foram submetidos à análise estatística, utilizando o software SISVAR versão 4.2 (Ferreira, 2003). No estudo de correlação, foram realizadas análises de regressão linear, obtendo-se a equação, o coeficiente de ajuste e o coeficiente de determinação da correlação de Pearson.

\section{RESULTADOS E DISCUSSÃO}

Comparando as formas de mensuração da quantidade de solo, quando as amostras foram tomadas por massa, não houve diferença entre os métodos de determinação, e, quando elas foram tomadas por volume, o teor de COS obtido pelo método volumétrico foi menor que o obtido pelo método colorimétrico, para o solo argiloso (Quadro 1). Maiores valores de COS foram obtidos quando as amostras foram tomadas em massa, independentemente do método utilizado, sendo a diferença, na média, entre as duas formas de tomada das amostras de $47 \%$ para o solo argiloso (NV), $44 \%$ para o de textura média (PVA) e $42 \%$ para o arenoso (LV).

Em relação ao uso de medidas de volumes das amostras de solo, considerado referência para muitos laboratórios de rotina de análise de solo, os resultados mostraram que a tomada das amostras em volume subestimou os teores de COS nos três solos analisados. Os menores teores de COS obtidos em amostras tomadas por volume podem estar relacionados às densidades diferentes do mesmo solo em condições de campo, sendo essas diferenças maiores em amostras de solo com alto teor de matéria orgânica. Conforme Raij \& Grohmann 
Quadro 1. Teor de carbono orgânico determinado pelos métodos colorimétrico e volumétrico de amostras tomadas em volume e massa, de três tipos de solo com texturas diferentes (argiloso, médio e arenoso)

\begin{tabular}{|c|c|c|c|c|}
\hline \multirow{2}{*}{ Solo $^{(1)}$} & \multicolumn{2}{|c|}{ Volumétrico } & \multicolumn{2}{|c|}{ Colorimétrico } \\
\hline & $\operatorname{Massa}^{(3)}$ & Volume & Massa & Volume \\
\hline & \multicolumn{4}{|c|}{$\mathrm{g} \mathrm{dm}^{-3}$} \\
\hline NV - Argiloso & $34,3 \mathrm{a} \mathrm{A}^{(2)}$ & 15,8 a $\mathrm{C}$ & 34,3 a $\mathrm{A}$ & 20,8 a B \\
\hline PVA - Médio & 10,3 с A & $5,5 \mathrm{~b} \mathrm{~B}$ & $10,5 \mathrm{c} \mathrm{A}$ & 6,1 с B \\
\hline LV - Arenoso & $26,3 \mathrm{~b} \mathrm{~A}$ & 15,9 a $\mathrm{B}$ & $27,4 \mathrm{~b} \mathrm{~A}$ & $15,2 \mathrm{~b} \mathrm{~B}$ \\
\hline CV (\%) & \multicolumn{4}{|c|}{15,2} \\
\hline
\end{tabular}

(1) NV (Nitossolo Vermelho), textura argilosa; PVA (Argissolo Vermelho-Amarelo), textura média; LV (Latossolo Vermelho), textura arenosa. ${ }^{(2)}$ Médias seguidas da mesma letra minúscula na coluna e maiúscula na linha não diferem significativamente pelo teste de Tukey $(p<0,05) .{ }^{(3)}$ Os valores originais da pesagem do solo-massa $\left(\mathrm{g} \mathrm{kg}^{-1}\right)$ foram transformados em volume $\left(\mathrm{g} \mathrm{dm}^{-3}\right)$, de acordo com as respectivas densidades de solo.

(1989), em estudos que requeiram maior precisão, pode ser útil obter medidas da densidade global de solos no campo, para efetuar as necessárias correções dos valores obtidos por meio de cachimbos, de maneira a expressar resultados de análises em volumes comparáveis de solos. Em virtude dessas observações, Ellert \& Betany (1995) demonstraram que, para avaliação de forma confiável da COS diante das diferenças de densidade do solo, as massas de solo devem ser equivalentes, razão pela qual sugeriram uma correção para a massa equivalente do solo, com intuito de eliminar a influência dessas diferenças.

Os coeficientes de correlação obtidos entre os métodos colorimétrico e volumétrico, nas amostras mensuradas por massa, mostraram-se iguais ou superiores a $90 \%$; essa resposta foi semelhante nas três classes de solos utilizados (Figura 1a,b,c).

Entretanto, quando as amostras foram mensuradas por volume, houve correlação superior a $90 \%$ entre o método colorimétrico e o volumétrico apenas no solo de textura média (Figura 2b). Para as amostras tomadas em volume, mesmo apresentando correlação significativa entre os métodos volumétricos e colorimétricos, verifica-se que a dispersão dos pontos em torno da reta foi alta, resultando em coeficientes de correlação baixos para o solo de textura argilosa $(\mathrm{r}=0,61)$ e arenosa $(\mathrm{r}=$ 0,64 ), respectivamente (Figura 2a,c). Essa resposta também pode estar relacionada ao teor de COS, visto que, no solo de textura média, obteve-se o menor teor de $\mathrm{COS}$ e o maior coeficiente da correlação; à medida que os teores de COS foram maiores em função das outras duas classes de solos estudadas, o coeficiente de correlação diminuiu.

Como o método colorimétrico possibilita ao mesmo tempo diminuir a quantidade de reagentes sem interferir na precisão da determinação de COS (Dias et al., 1991), as correlações apresentadas mostraram que essa observação só é verdadeira quando as amostras são mensuradas por massa, visto que apresentou altas correlações com o método volumétrico, com coeficientes de 0,99, 0,97 e 0,90, para os solos de textura argilosa (NV), média (PVA) e arenosa (LV), respectivamente, ou quando as amostras são mensuradas por volume para o solo de
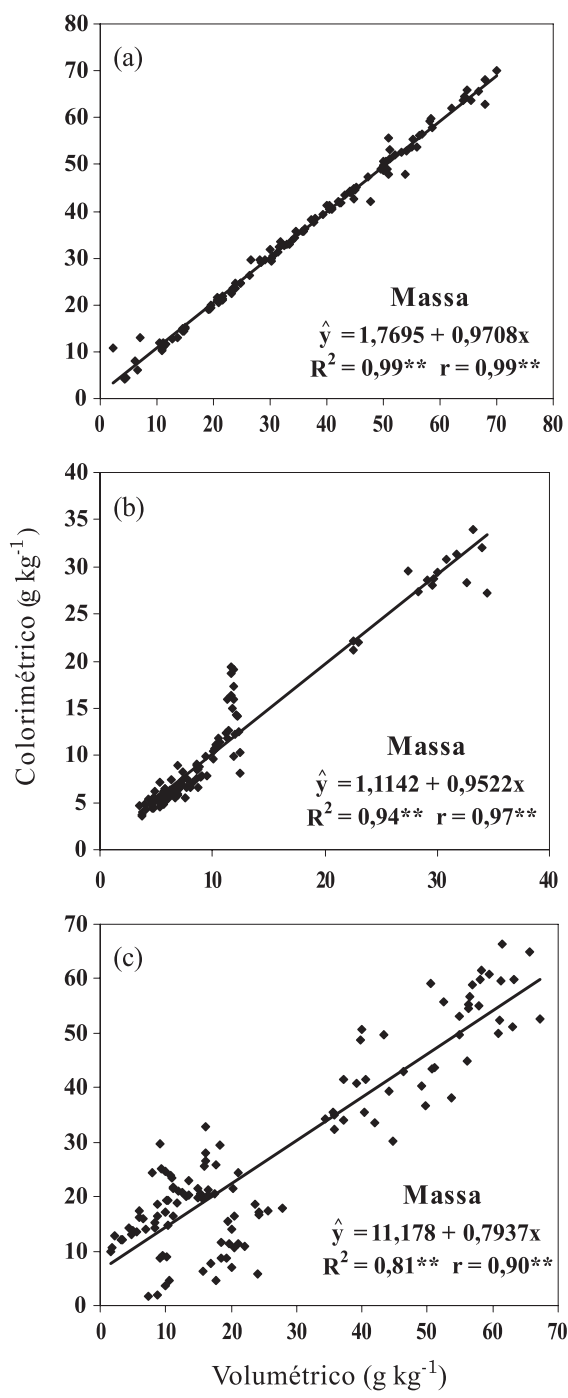

Figura 1. Relação entre os teores de carbono orgânico (COS) determinados pelo método colorimétrico e volumétrico, de amostras mensuradas por massa, de um solo de textura argilosa - NV (a), de um solo de textura média - PVA (b) e de um solo de textura arenosa - LV (c), bem como os respectivos coeficientes de determinação $\left(\mathbf{R}^{2}\right)$ e de correlação $(r)$. ** significativo $(\mathrm{p}<0,01)$. 

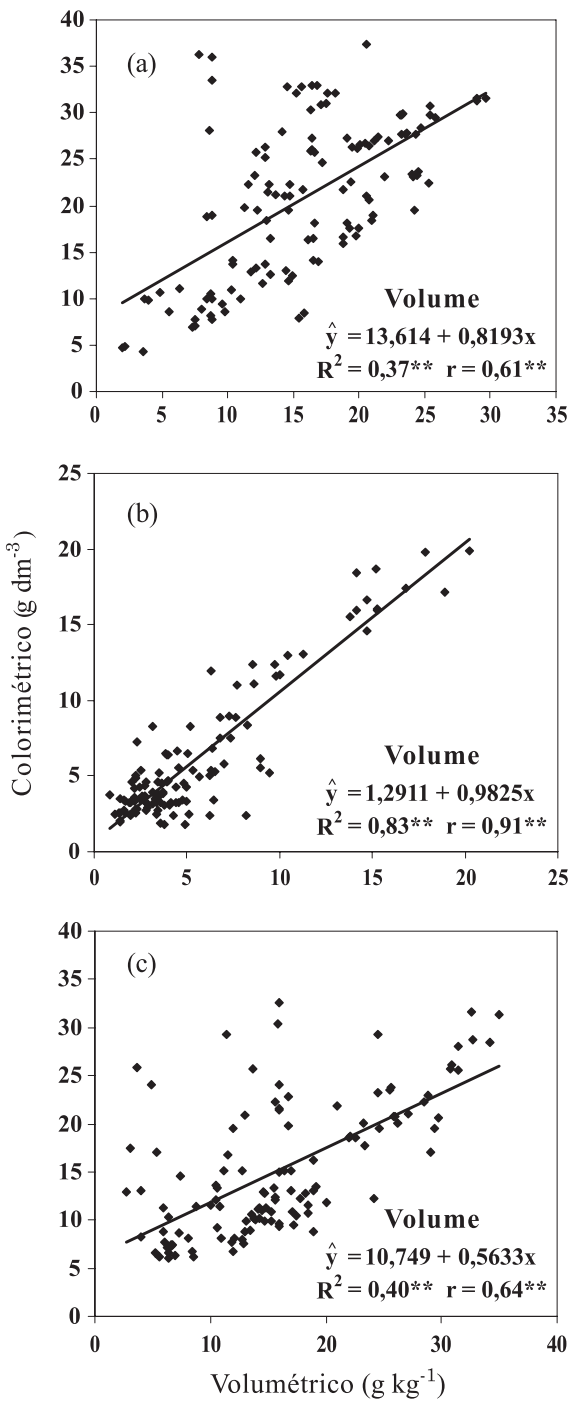

Figura 2. Relação entre os teores de carbono orgânico (COS) determinados pelo método colorimétrico e volumétrico de amostras mensuradas por volume, de um solo de textura argilosa -NV (a), de um solo de textura média - PVA (b) e de um solo de textura arenosa - LV (c), bem como os respectivos coeficientes de determinação $\left(\mathbf{R}^{2}\right)$ e de correlação $(r)$.*** significativo $(\mathrm{p}<0,01)$.

textura média (NV), o qual apresentou menor teor de COS. Segundo Rheinheimer et al. (2008), a economia de reagentes proporciona vantagens no tratamento e manipulação de efluentes de laboratório de análises de solos. O método colorimétrico pode ainda diminuir o erro nos resultados de análise de COS do solo, pois não apresenta o problema de contar com o sentido visual para se verificar o ponto exato em que todo o dicromato reage com o $\mathrm{Fe}^{2+}$, acarretando mudança de coloração da solução.

A relação do teor de COS determinado em amostras de solo tomadas pela massa em função das tomadas por volume, pelo método colorimétrico, apresentou coeficientes de correlação iguais ou superiores a $90 \%$ nos solos de textura média e textura arenosa, que têm menor teor de COS (Figura 3b,c). Para o solo argiloso, com maior teor de COS, verificou-se baixo coeficiente de correlação $(r=0,28)$ entre amostras tomadas em massa e em volume (Figura 3a).

Quanto à relação entre as determinações feitas nas amostras mensuradas por massa em função das mensuradas por volume, pelo método volumétrico, obteve-se correlação superior a $90 \%$ somente no solo
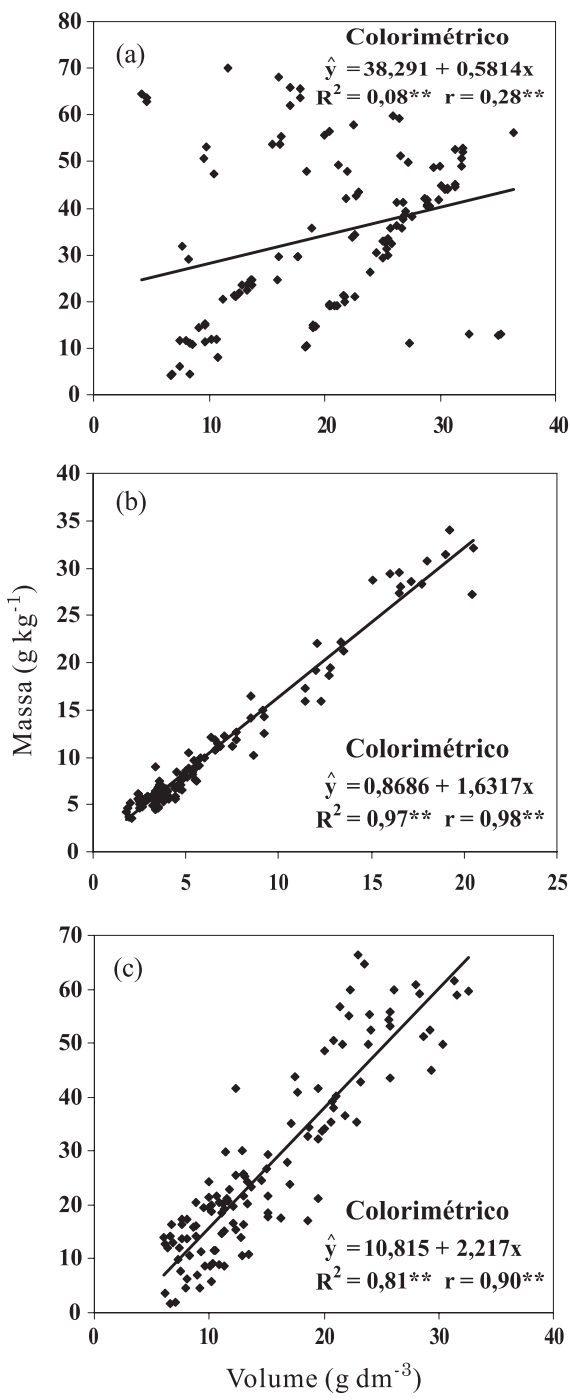

Figura 3. Relação entre os teores de carbono orgânico (COS) determinados em amostras de solo mensuradas por massa em função das mensuradas por volume, pelo método colorimétrico, de um solo de textura argilosa -NV (a), de um solo de textura média - PVA (b) e de um solo de textura arenosa - LV (c), bem como os respectivos coeficientes de determinação $\left(R^{2}\right)$ e de correlação (r). ** significativo $(\mathrm{p}<0,01)$. 
de textura média - PVA e com menor teor de COS (Figura 4b). No solo de textura arenosa - LV e com teor de COS intermediário entre os três solos, assim como no de textura argilosa - NV e maior teor de COS, os valores do coeficiente de ajuste da correlação diminuíram, com valores de $\mathrm{r}$ iguais a 0,61 e 0,41 , respectivamente (Figura 4a,c).

De modo geral, todas as correlações analisadas para o solo de menor teor de COS mostraram coeficiente de ajuste superior a $90 \%$; à medida que essas análises estatísticas foram feitas nos outros
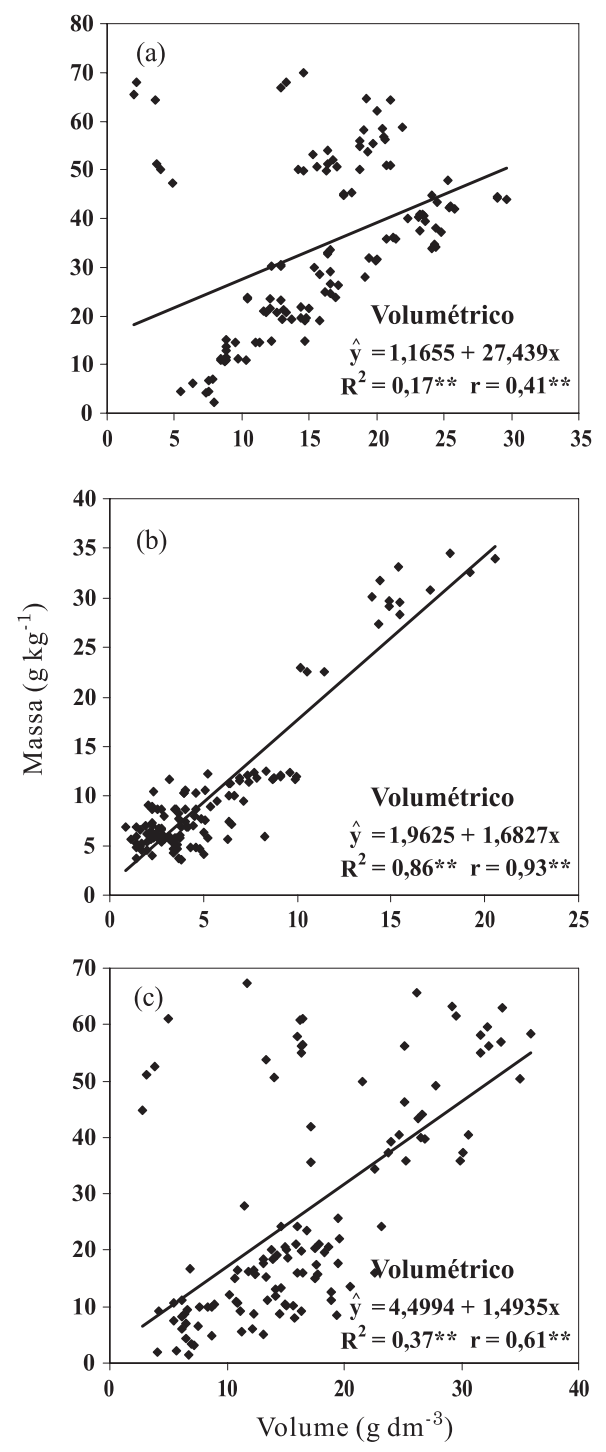

Figura 4. Relação entre os teores de carbono orgânico (COS) determinados em amostras de solo mensuradas por massa e volume, pelo método volumétrico, de um solo de textura argilosa -NV (a), de um solo de textura média - PVA (b) e de um solo de textura arenosa - LV (c), bem como os respectivos coeficientes de determinação $\left(R^{2}\right)$ e de correlação $(r)$. ** significativo $(p<0,01)$. dois solos, houve diminuição dos valores de ajuste da correlação (r) em função do aumento do teor de COS nesses diferentes solos.

\section{CONCLUSÕES}

1. Quando a mensuração é por massa, o método colorimétrico tem correlação $>$ de 0,9 com o método volumétrico.

2. Quando as amostras são mensuradas por volume, só se observa correlação $>$ de 0,9 para as amostras com teor de $\mathrm{C}$ mais baixo.

3. A mensuração das amostras de solo por volume ou massa, quando utilizadas nas determinações do COS, altera os resultados, independentemente de o método ser colorimétrico ou volumétrico.

4. As determinações de COS feitas em solos com menor teor de COS apresentam menor variação entre os dados pelos diferentes métodos laboratoriais que os solos com maior teor de COS.

\section{LITERATURA CITADA}

ABREU, C.A.; ABREU, M.F.; SOARES, L.H. \& ANDRADE, J.C. The effects of the DTPA extraction conditions on the determination of micronutrients in Brazilian soils. Comm. Soil Sci. Plant Anal., 28:1-11, 1997.

CARDOSO, E.L.; SILVA, M.L.N.; CURI, N.; FERREIRA, M.M. \& FREITAS, D.A.F. Qualidade química e física do solo sob vegetação arbórea nativa e pastagens no Pantanal Sul-Mato-Grossense. R. Bras. Ci. Solo, 35:613-622, 2011.

CONCEIÇÃO, M.; MANZATTO, C.V.; ARAÚJO, W.S.; MARTIN NETO, L.; SAAB, S.C.; CUNHA, T.J.F. \& FREIXO, A.A. Estudo comparativo de métodos de determinação do teor de matéria orgânica em solos orgânicos do Estado do Rio de Janeiro. 3.ed. Brasília, Embrapa Solos, 1999. p.1-5.

CUNHA, E.Q.; STONE, L.F.; MOREIRA, J.A.A.; FERREIRA, E.P.B.; DIDONET, A.D. \& LEANDRO, W.M. Sistemas de preparo do solo e culturas de cobertura na produção orgânica de feijão e milho: I - Atributos físicos do solo. R. Bras. Ci. Solo, 35:589-602, 2011.

DIAS, L.E.; JUCKSCH, I.; RICCI, M. S.F. \& ALVAREZ V., V.H. Comparação de diferentes métodos de determinação de carbono orgânico em amostras de solos. R. Bras. Ci. Solo, 15:157-162, 1991.

ELLERT, B.H. \& BETTANY, J.R. Calculation of organic matter and nutrients stored in soils under contrasting management regimes. Canadian J. Soil Sci., 75:529-538, 1995.

EMPRESA BRASILEIRA DE PESQUISA AGROPECUÁRIA EMBRAPA. Manual de análises químicas de solos, plantas e fertilizantes. Brasília, Embrapa Comunicação para Transferência de Tecnologia, 1999. 370p. 
FERREIRA, D. F. Sisvar versão 4.2. DEX/UFLA, 2003.

GATTO, A.; BARROS, N.F.; NOVAIS, R.F.; SILVA, I.R.; SÁ MENDONÇA, E. \& VILLANI, E.M.A. Comparação de métodos de determinação do carbono orgânico em solos cultivados com eucalipto. R. Bras. Ci. Solo, 33:735-740, 2009

LA SCALA JR, N.; LOPES, A.; MARQUES JÚNIOR, J. \& PEREIRA, G.T. Carbon dioxide emissions after application of tillage systems for a Dark Red Latossol in Southern Brazil. Soil Till. Res., 62:163-166, 2001.

LIEROP, W.van. Effect of assumptions on accuracy for analytical results and liming recomendations when testing a volume or weight of soil. Comm. Soil Sci. Plant Anal., 20:121-137, 1989.

NELSON, D.W. \& SOMMERS, L.E. Total carbon, organic carbon and organic matter. In: SPARKS, D.L.; PAGA, A.L.; HELMKE, P.A.; LOEPPERT, R.H.; SOLTANPOUR, P.N.; TABATABAI, M.A.; JOHNSTON, C.T. \& SUMMER, M.E., eds. Methods of soil analysis: Chemical methods. 3.ed. Madison, Soil Science Society of America, 1996. p.961-1010.

QUAGGIO, J.A. \& RAIJ, B.van. Comparação de métodos rápidos para a determinação da matéria orgânica em solos. R. Bras. Ci. Solo, 3:184-187, 1979.

RAIJ, B.van; ANDRADE, J.C.; CANTARELLA, H. \& QUAGGIO, J.A. Determinação da Matéria Orgânica. In: RAIJ, B.van; ANDRADE, J.C.; CANTARELLA, H. \& QUAGGIO, J.A., eds. Análise química para avaliação da fertilidade de solos tropicais. Campinas, Instituto Agronômico de Campinas, 2001. p.189-199.

RAIJ, B.van \& BATAGLIA, O.C. Análise de laboratório. In: OLIVEIRA, A.J.; GARRIDO, W.E.; ARAUJO, J.D. \& LOURENÇO, S., eds. Métodos de pesquisa em fertilidade do solo. Brasília, Embrapa-Sea, 1991. p.81-101.
RAIJ, B.van. \& GROHMANN, F. densidade global de solos medida com anel volumétrico e por cachimbagem de terra fina seca ao ar. Bragantia, 48:125-130, 1989.

RHEINHEIMER, D.S.; CAMPOS, B.C.; GIACOMINI, S.J.; CONCEIÇÃO, P.C. \& BORTOLUZZI, E.C. Comparação de métodos de determinação de carbono orgânico total no solo. R. Bras. Ci. Solo, 32:435-440, 2008.

SILVA, I.R. \& MENDONÇA, E.S. Matéria orgânica do solo. In: NOVAIS, R.F.; ALVAREZ V., V.H.; BARROS, N.F.; FONTES, R.L.F.; CANTARUTTI, R.B. \& NEVES, J.C.L., eds. Fertilidade do solo. Viçosa, MG, Sociedade Brasileira de Ciência do Solo, 2007. p.275-374.

TEDESCO, M.J.; VOLKWEISS, S.J. \& BOHNEN, H. Análises de solo, plantas e outros materiais. Porto Alegre, Universidade Federal do Rio Grande do Sul, 1985. 188p. (Boletim Técnico de Solos, 5)

TEDESCO, M.J.; GIANELLO, C.; BISSANI, C.A.; BOHNEN, H. \& VOLKWEISS, S.J. Análises de solo, plantas e outros materiais. 2.ed. Porto Alegre, Universidade Federal do Rio Grande do Sul, 1995. 174p. (Boletim Técnico, 5)

VASCONCELOS, R.F.B.; CANTALICE, J.R.B.; SILVA, A.J.N.; OLIVEIRA, V.S. \& SILVA, Y.J.A.B. Limites de consistência e propriedades químicas de um Latossolo Amarelo distrocoeso sob aplicação de diferentes resíduos da canade-açúcar. R. Bras. Ci. Solo, 34:639-648, 2010.

WALKLEY, A.A. Critical examination of a rapid method for determining organic carbon in soils: Effect of variations in digestion conditions and of inorganic soil constituents. Soil Sci., 63:251-263, 1947.

WALKLEY, A. \& BLACK, I.A. An examination of the Degtjareff method for determining soil organic matter and a proposed modification of the chromic acid titration method. Soil Sci., 37:29-38, 1934. 
